\title{
O que será do Brasil e do SUS?
}

\section{What will be of Brazil and SUS?}

\section{Que sera de Brasil y del SUS?}

\author{
Ademar Arthur Chioro dos Reis, \\ arthur.chioro@unifesp.br | https://orcid.org/0000-0001-7184-2342 \\ ${ }^{1}$ Universidade Federal de São Paulo, Escola Paulista de Medicina, Departamento de Medicina Preventiva. São Paulo, \\ SP, Brasil.
}

a Doutorado em Saúde Coletiva pela Universidade Federal de São Paulo.

\section{Resumo}

A nota apresenta efeitos do golpe jurídico-parlamentar de 2016 e avalia seus reflexos na profunda crise política, econômica e social que assola o Brasil. Assume a dificuldade de projetar o futuro do Sistema Único de Saúde (SUS), que completa 30 anos em outubro, nesse contexto. Reafirma o impacto do congelamento de gastos públicos nas políticas sociais estabelecidas em governos anteriores e em como as reformas confrontam diretamente com a Constituição de 1988, que introduziu o conceito de saúde como direito e dever do Estado. Por fim, relembra o papel dos atores históricos na construção do SUS e da importância da mobilização dos movimentos populares para que, perante as eleições federais e estaduais, seja possível defender o SUS que se quer.

Palavras-chave: Brasil; Sistema Único de Saúde; Estado Democrático de Direito; Relação públicoprivado; Política de austeridade.

\begin{abstract}
The note presents effects of the legal-parliamentary coup of 2016 and evaluates its reflections in the deep political, economic, and social crisis that plagues Brazil. It assumes the difficulty of projecting the future of the Sistema Único de Saúde (Unified Health System - SUS), which turns 30 years old in October, in this context. It reaffirms the impact of the freezing of public spending on social policies established in previous governments, and on how the reforms directly confront the Constitution of 1988, which had introduced the concept of health as a right and duty of the State. Finally, the note recalls the role of historical actors in building SUS and the importance of the mobilization of popular movements so that, before federal and state elections, it is possible to defend the SUS that is wanted.
\end{abstract}

Keywords: Brazil; Unified Health System; Democratic state; Public-private relationship; Austerity measures. 


\section{Resumen}

La nota presenta efectos del golpe jurídico-parlamentar de 2016 y evalúa sus reflejos en la profunda crisis política, económica y social que asola a Brasil. Asume la dificultad de proyectar el futuro del Sistema Único de Salud (SUS), que cumple 30 años en octubre, en ese contexto. Reafirma el impacto de la congelación del gasto público en las políticas sociales establecidas en gobiernos anteriores y en cómo las reformas confrontan directamente la Constitución de 1988, que introdujo el concepto de salud como derecho y deber del Estado. Por último, recuerda el papel de los actores históricos en la construcción del SUS y la importancia de la movilización de los movimientos populares para que, ante las elecciones federales y estatales, sea posible defender el SUS que se quiere.

Palabras clave: Brasil; Sistema Único de Salud (SUS); Estado democratico de derecho; Relación públicoprivada; Política de austeridad.

O que aconteceu com o Brasil? Esta é a pergunta feita por quem vive no exterior, aturdido com as mudanças bruscas observadas no país que tinha se tornado a sexta potência econômica e surgia no cenário internacional como nação com potencial para liderar uma nova ordem mundial. O que acontecerá com o país, perguntamos os que aqui vivemos, independentemente de termos ou não apoiado o golpe jurídicoparlamentar que depôs a presidente Dilma e culminou com a prisão de Lula, o mais bem avaliado presidente da história e figura pública por excelência com condições de liderar a retomada da normalidade políticainstitucional, recolocando o Brasil nos trilhos?

Não se trata de tarefa fácil analisar a conjuntura política brasileira e, nesse complexo contexto, o que poderá acontecer com o Sistema Único de Saúde (SUS), que completa 30 anos em outubro. Não é possível ainda compreender as raízes mais estruturais do golpe de 2016. Produzido a partir da manipulação política e sustentado pelos setores de comunicação, empresariais e financeiro, teve respaldo de amplos segmentos da população, em particular da classe média, embalada pelo discurso de combate à corrupção endêmica que marca a relação público x privado e nosso sistema político-eleitoral desde priscas eras. Entretanto, já é possível perceber suas consequências. O país mergulhou numa profunda crise política, econômica e social, com efeitos deletérios sobre a qualidade de vida e de saúde da população.

Os que apoiaram o impeachment e se regozijam da prisão de Lula, almejada desde o final dos anos 1970, não conseguem mais escamotear o fracasso do golpe e as reais intenções da aliança conservadora que o liderou. A inexistência, há poucos meses da eleição, de qualquer candidato de centro ou direita, apoiador explícito ou enrustido do golpe, com chances de representar a manutenção do projeto golpista é expressão disso. Corremos o risco, sem Lula e a união da esquerda, de ascender à Presidência da República um ex-milico fascista, apoiado pelos setores mais retrógrados da sociedade, 'saídos do armário' após as manifestações de 2013 e que se fortaleceram a partir da recusa, pelo candidato das oposições derrotado por Dilma no segundo turno, de reconhecer o resultado eleitoral, primado básico da democracia, abrindo espaço para o 'plano B' das elites e a colocação em prática de uma cartilha conservadora em ritmo alucinante.

$O$ resultado se traduz no recrudescimento da violência urbana, na criminalização dos movimentos sociais e de suas lideranças, no descontrole de índices que repercutem drasticamente sobre os mais pobres, com aumento do desemprego (14\%), do dólar $(\mathrm{R} \$ 4,00)$, do gás de cozinha $(\mathrm{R} \$ 75,00)$, da gasolina $(\mathrm{R} \$ 5,00)$ e do diesel, que fez eclodir a greve dos caminhoneiros (a serviço de quem mesmo?). Essa é apenas a face mais visível da desgraça que se abate sobre os brasileiros. Muitos daqueles que foram às ruas 'em nome da moral e dos bons costumes', alardeando a luta contra a corrupção (com patos da Fiesppi, camisa da CBF ${ }^{\mathrm{ii}}$

i Federação das Indústrias do Estado de São Paulo.

ii Confederação Brasileira de Futebol. 
e ao som de panelas) já percebem que o golpe foi liderado pelos setores implicados com a corrupção e se questionam sobre os rumos que tomará o Brasil.

Desde o fim do regime militar, a democracia brasileira nunca esteve tão ameaçada. Há os que nas mídias sociais bradam pela suspensão das eleições de 2018 e a instituição de um governo jurídico-militar capaz de 'restaurar a ordem social'. As últimas manifestações da caserna e as relações estabelecidas por agentes do Ministério Público, sistema judiciário e da Polícia Federal, que têm pautado os rumos do país de forma seletiva, em ritmo alucinante, atropelando os mais elementares princípios que regem o Estado Democrático de Direito, indicam que essa tese precisa ser cautelosamente considerada. Mais do que isso, é preciso compreender que o golpe foi concebido e apoiado para a 'restauração da ordem conservadora', como já apontava Bourdieu, ao analisar, décadas antes, a cartilha neoliberal sendo implementada na Europa ocidental. ${ }^{1}$

É como se as 'portas represadas do inferno' tivessem sido repentinamente abertas e a agenda antipopular, só factível em tempos de golpe, de regimes de exceção, pudesse ser levada a cabo, contra os interesses da ampla maioria da população. A reforma trabalhista, a entrega do pré-sal às multinacionais, a Emenda Constitucional 95 (EC-95) que limita por 20 anos os gastos públicos (mas mantém o pagamento à banca), a proposta de reforma da Previdência, entre outros, são exemplos da volúpia com que o governo Temer, atendendo aos interesses daqueles que o sustentam e contando com a docilidade de uma maioria fisiológica, construída à base da farra dos cargos públicos e emendas parlamentares - tendo o Ministério da Saúde (MS) como fiador -, em tempo recorde vem destruindo as conquistas obtidas em décadas de lutas por cidadania e justiça social.

Os governos Lula e Dilma tiveram êxitos e limites. Tive a oportunidade de vivenciá-los por dentro, como diretor e depois como ministro da Saúde. Não fizemos a reforma política necessária (mãe de todas as reformas). Nem a do sistema de justiça. Ficamos devendo uma reforma administrativa (nossa estrutura de gestão ainda é a herdada da ditadura, só alterada pela criação das agências executivas, das Organizações da Sociedade Civil de Interesse Público - Oscip e das Organizações Sociais - OS no governo Fernando Henrique Cardoso - FHC). Não democratizamos os meios de comunicação. Não fizemos a reforma tributária para taxar as grandes fortunas e heranças. Desconsideramos a necessidade de politizar a sociedade e construir uma nova cultura política. Não enfrentamos a chaga da corrupção endêmica que assola (e ainda campeia, livre, leve e solta) nosso país. A direita foi subestimada e a opção de produzir inclusão pela lógica de consumo, pela produção de uma nova e robusta classe média, não sobreviveu à primeira crise econômica. Nos últimos anos o sistema financeiro, a elite empresarial e o latifúndio se locupletaram o quanto puderam. Mas é preciso reconhecer também que as políticas públicas inclusivas empreendidas fizeram milhões de brasileiros viver mais e melhor, ter casa própria, energia elétrica, a oportunidade de estudar numa escola técnica e cursar a universidade, antes privilégios das elites. Elegemos Lula e Dilma, mas não constituímos maioria entre as forças progressistas e democráticas no Congresso Nacional para produzir a governabilidade necessária, ensejando alianças com setores conservadores, clientelistas e fisiológicos que, sob a liderança de Eduardo Cunha \& Cia, ousaram poder mais.

Assim deve ser compreendido o desmonte do Estado brasileiro em curso. É um equívoco achar que apenas o SUS corre perigo. A diminuição de recursos para a educação e as universidades públicas, para as políticas de C\&T, o desmonte insidioso do Bolsa Família, entre outros, demonstra que a ação conservadora em curso é agressiva e radical. Os tempos são de 'tudo ou nada' para os golpistas.

É nesse contexto, complexo e tenebroso, que o SUS completa 30 anos. Nunca, a ideia-força produzida desde a luta pela redemocratização, que culminou na garantia constitucional da saúde como direito universal, público e gratuito, e dever do Estado, esteve tão ameaçada.

A desastrosa política econômica do governo Temer-Meirelles gerou o agravamento da crise social e seus impactos na saúde já são evidentes, como o fechamento ou diminuição de oferta de serviços. A política de 
austeridade elevará a mortalidade infantil criminosamente em 8,6\% até 2030. Isso representa mais de 20 mil mortes nos próximos 12 anos, com impacto nos municípios mais pobres, determinadas pelo aumento da pobreza e redução de cobertura de programas sociais, em particular o Bolsa Família e a Estratégia da Saúde da Família². A mortalidade na infância já aumentou de 14,3 óbitos por 1.00o habitantes, em 2015, para 14,9 em 2016. Os óbitos evitáveis, em 2016, de crianças de 1 a 5 anos de idade, aumentaram 11\%. A taxa de mortalidade infantil cresceu, após uma sustentável tendência de queda, e passou de 12,4, em 2015, para 12,7 óbitos de menores de 1 ano para cada 1.000 nascidos vivos em $2016 .^{3}$

Após três décadas de luta pela implantação e financiamento do SUS, pela municipalização da saúde (década de 1980), pela regionalização com integralidade (anos 1990) e por garantia de acesso com qualidade (2003-2015), voltamos à pauta pré-SUS: lutar para garantir a existência de um sistema universal de saúde em nosso país.

A saúde como política pública sempre esteve fortemente associada ao papel assumido pelo Estado frente ao modelo de desenvolvimento econômico e social. Os sucessivos períodos de crises econômicas e políticas interferiram significativamente nos seus rumos. O SUS, criado em um cenário de redemocratização e ampliação dos direitos sociais, é uma conquista política da sociedade brasileira. Desde a sua criação observou-se constante tensionamento entre as áreas econômicas dos diferentes governos (Collor, Itamar, FHC, Lula e Dilma) e os representantes oficiais da saúde (ministros e equipe gestora). No governo Temer, pela primeira vez, os agentes oficiais da saúde enunciam um discurso em concordância com a área econômica. Esse fenômeno revela a pretensão de uma nova ordem social, em que o SUS seja direcionado para as periferias urbanas marginais e a pobreza rural, através de uma rede extensiva de serviços de baixo custo. Retoma-se, agora de maneira explícita e agressiva, o movimento já ensaiado nos anos 1990, nos governos Collor e FHC, de estratificação de clientelas.

A retórica de reformas, centrada em mudanças no modelo fiscal, descontrole de gastos, melhoria de controles e de um 'SUS menor', é uma falácia. A proposta de criação de planos populares de saúde afronta a universalidade e impõe redução de direitos.

A Emenda Constitucional 95/16 congela os gastos públicos por vinte anos, sem considerar as mudanças demográficas, epidemiológicas e a necessidade de incorporação tecnológica do SUS. Fere de morte o SUS e desconsidera as necessidades de saúde da população, de expansão da rede para cobrir vazios assistenciais e a própria inflação setorial. Pior, desvincula os gastos sociais de qualquer crescimento de receitas nos próximos 20 anos $^{4}$. Torna inviáveis programas como o Mais Médicos, as Unidades de Pronto Atendimento (UPA), o Serviço de Atendimento Móvel de Urgência (Samu), a Farmácia Popular, a Saúde da Família, o Programa Nacional de Imunizações, entre outros. As reformas impostas destroem políticas universalizantes e inclusivas que foram construídas nos últimos anos e são resultado dos grupos de interesse que sustentam o golpe, sob os auspícios dos setores mais retrógrados do país em aliança com o capital.

A Constituição de 1988, ao introduzir o conceito de saúde como direito e dever do Estado, estabeleceu uma nova ordem civilizatória, com ampliação dos direitos sociais. Trata-se de uma grande conquista da sociedade brasileira. O SUS é indispensável e todos se beneficiam. Mesmo cronicamente subfinanciado e com diversos problemas em sua implementação, garantiu avanços comprovados pelas melhorias nos indicadores de saúde, como mortalidade infantil e expectativa de vida ao nascer. Sua destruição significará a barbárie para milhões de brasileiros que dele dependem e que jamais terão acesso aos serviços privados na lógica de mercado. O desmonte já está em curso e pode ser exemplificado pelas mudanças recentes na Política Nacional de Atenção Básica, na Farmácia Popular, no fim dos blocos de financiamento (que em cenário de restrição financeira reduzirão recursos para a atenção básica e a vigilância em saúde). Passa, ainda, pela demissão de gestores e técnicos competentes e comprometidos com o SUS, muitos trabalhando no MS desde a gestão de Adib Jatene, e a indicação de apaniguados políticos sem nenhuma capacidade ou experiência técnica. 
Mais, o MS transformou-se em um balcão de negócios. Na área da informática, o Tribunal de Contas (TCU) suspendeu programa de 15,1 bilhões de reais do MS para informatização de mais de 29 mil unidades básicas de saúde (UBS) pelas evidências de que haveria facilitação e direcionamento pelas prefeituras para livre escolha de prestadores5. O TCU irá ainda auditar o Fundo Nacional de Saúde porque $71 \%$ dos recursos de emendas de relatoria teriam sido anomalamente distribuídas em seis estados, comandados por caciques do Partido Progressista (PP), partido que controla o $\mathrm{MS}^{6}$.

Nesse contexto de fragilização e desmonte, o mercado privado passa a disputar publicamente seus projetos de ampliação do controle dos fundos públicos. Como nos diz Gastão Wagner, presidente da Associação Brasileira de Saúde Coletiva (Abrasco), "o MS transformou-se em garoto-propaganda e incentivador do mercado em saúde". A capacidade de compra de planos de saúde pela população, entretanto, nunca ultrapassou 22\%, o teto aparente de consumo. O mercado sabe disso e anseia na verdade é pelo retorno ao passado, quando operavam sem nenhuma regulação governamental.

Para viabilizar o SUS, será necessário garantir financiamento suficiente e permanente. É impossível manter um sistema universal e integral com um gasto público na faixa de R \$ 3,20 habitante/dia. A EC95 impede a expansão em termos reais das despesas, sendo possível, inclusive, a diminuição (em termos nominais e reais) dos gastos federais em saúde, já observada em 2018.

Temos ainda que lidar com uma crise de legitimidade. Após décadas de financiamento e privilégios para o setor privado, vendeu-se para sociedade a ideia de que seus problemas se resolverão com acesso a planos de saúde. Isso se tornou sonho de consumo da nova classe média, que entretanto se depara com a tragédia da saúde suplementar que lhe é ofertada.

Temos, entretanto, força e capacidade de resistir. Atores historicamente presentes na formulação e construção do SUS têm se colocado em sua defesa, como o Conselho Nacional de Saúde (CNS), a Abrasco, o Centro Brasileiro de Estudos de Saúde (Cebes), sindicatos, partidos políticos de esquerda e movimentos sociais. Essas forças precisarão mobilizar outros segmentos e a sociedade, em geral, para o embate eleitoral de 2018. Pela primeira vez na história das eleições presidenciais pós-redemocratização teremos em disputa diferentes projetos para a saúde e propostas que visam acabar ou desfigurar o SUS para favorecer o mercado. Até então, em maior ou menor grau, todos os candidatos reafirmaram seu compromisso com o SUS. Portanto, esse será um momento estratégico de disputa pelo SUS que queremos. Da mesma forma, torna-se importantíssima a eleição de deputados federais e senadores comprometidos com o SUS, porque o jogo para mudar a Constituição terá que ser jogado no Parlamento (e nas ruas).

A construção de uma frente política ampla, de esquerda e democrática, experimentada com sucesso em outros países, comprometida com um projeto em que a defesa do SUS, junto com outras pautas republicanas e de interesse popular, tenha centralidade, é fundamental nesse momento histórico que atravessamos.

Nem tudo está perdido, mas não está dado que o SUS será mantido e aperfeiçoado. Temos a possibilidade de retomar a construção de um país para todos e todas. Lembro-me, entretanto, do que nos dizia David Capistrano. Nessas horas, é preciso mobilizar nossa capacidade de indignação e lutar com todas as forças pela democracia e justiça social. O SUS é muito mais do que um marco organizativo-institucional. É também espaço de luta, um projeto ético-político civilizatório que se soma às demais lutas por uma sociedade justa e fraterna. Portanto, precisamos nos enlaçar às demais pautas democráticas da sociedade e fazer as alianças necessárias para que a saúde esteja incluída na pauta central do debate político nacional. Aí, talvez, será possível contar uma bela história quando o SUS completar 40 anos... 


\section{Referências}

1. Bourdieu P. Contrafogos: táticas para enfrentar a invasão neoliberal. Rio de Janeiro: Jorge Zahar Ed. 1998.

2. Rasella D; Basu D; Hone T, Paes-Sousa R, Ocké-Reis CO, Millett C. Child morbidity and mortality associated with alternative policy responses to the economic crisis in Brazil: a nationwide microsimultation study. PLoS Med. 2018;15(5):e1002570. doi: https://doi.org/10.1371/journal. pmed.1002570

3. Velleda L. Efeito do golpe, mortalidade na infância cresce, depois de 15 anos de redução. Rede Brasil Atual; 19 maio 2018 [citado 2018 maio 20]. Disponível em: http://www.redebrasilatual.com.br/ revistas/140/efeito-do-golpe-mortalidade-infantil-cresce-depois-de-15-anos-de-reducao

4. Reis AAC, Soter APM, Furtado LAC, Pereira SSS. Tudo a temer: financiamento, relação público e privado e o futuro do SUS. Saúde debate. 2016;40(especial):122-135. doi: http://dx.doi.org/10.1590/0103$11042016 \mathrm{~s} 11$

5. Camarotto M. TCU manda suspender programa de R\$15 bi do Ministério da Saúde. Valor Econômico; 21 maio 2018. [citado 2018 maio 22]. Disponível em: http://www.valor.com.br/brasil/5537029/tcu-mandasuspender-programa-de-r-15-bi-do-ministerio-da-saude

6. Matais, A. TCU quer saber se PP usou fundo de saúde para atrair deputados. Estadão; 19 maio 2018. [citado 2018 maio 22]. Disponível em: https://politica.estadao.com.br/blogs/coluna-do-estadao/tcuquer-saber-se-pp-usou-fundo-de-saude-para-atrair-deputados/

7. Abrasco. Associação Brasileira de Saúde Coletiva. Gastão Wagner: "O Ministério da Saúde transformouse em garoto-propaganda e incentivador do desenvolvimento do mercado de saúde". Abrasco; 21 maio 2018. [citado 2018 maio 23]. Disponível em: https://www.abrasco.org.br/site/outras-noticias/opiniao/ gastao-wagner-o-ministerio-da-saude-transformou-se-em-garoto-propaganda-e-incentivador-dodesenvolvimento-do-mercado-da-saude/34239/ 